\title{
International
}

\section{APSA International Membership}

Total international membership of the American Political Science Association-as of February, 2017-is 2,548 members, which is nearly 20\% of APSA's membership. The association greatly appreciates its international members! The number of members per country is listed below.

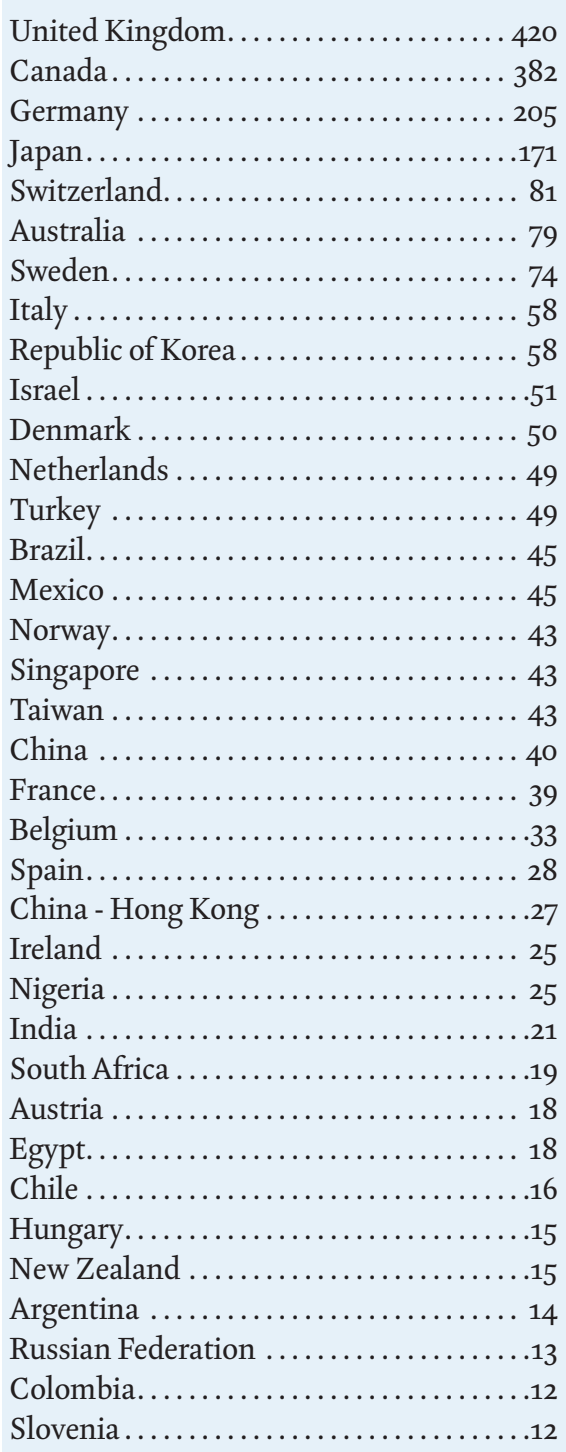

Portugal ....................... 10

United Arab Emirates ............... 10

Malaysia .........................

Finland........................ 8

Greece.......................... 8

Lebanon......................... 8

Ghana............................

Kuwait ............................

Poland...........................

Romania .........................

Czech Republic .....................6

Dominican Republic ..................6

Cyprus ........................... 5

Indonesia......................... 5

Kazakhstan....................... 5

Philippines ....................... 5

Qatar............................ 5

Cameroon ........................ 4

Uganda......................... 4

Ethiopia..........................

Jordan............................ 3

Kenya $. . . \ldots \ldots \ldots \ldots \ldots \ldots \ldots \ldots \ldots . . . \ldots \ldots$

China - Macao.......................

Morocco..........................

Mozambique ....................... 3

Palestine ..........................

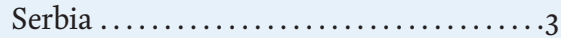

Slovakia.......................... 3

Thailand $\ldots \ldots \ldots \ldots \ldots \ldots \ldots \ldots \ldots \ldots, \ldots, \ldots$

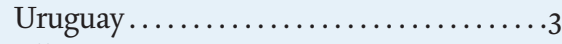

Albania............................2

Bangladesh.......................

Botswana..........................

Bulgaria .........................

Ecuador...$\ldots \ldots \ldots \ldots \ldots \ldots \ldots \ldots \ldots \ldots$

Estonia..........................

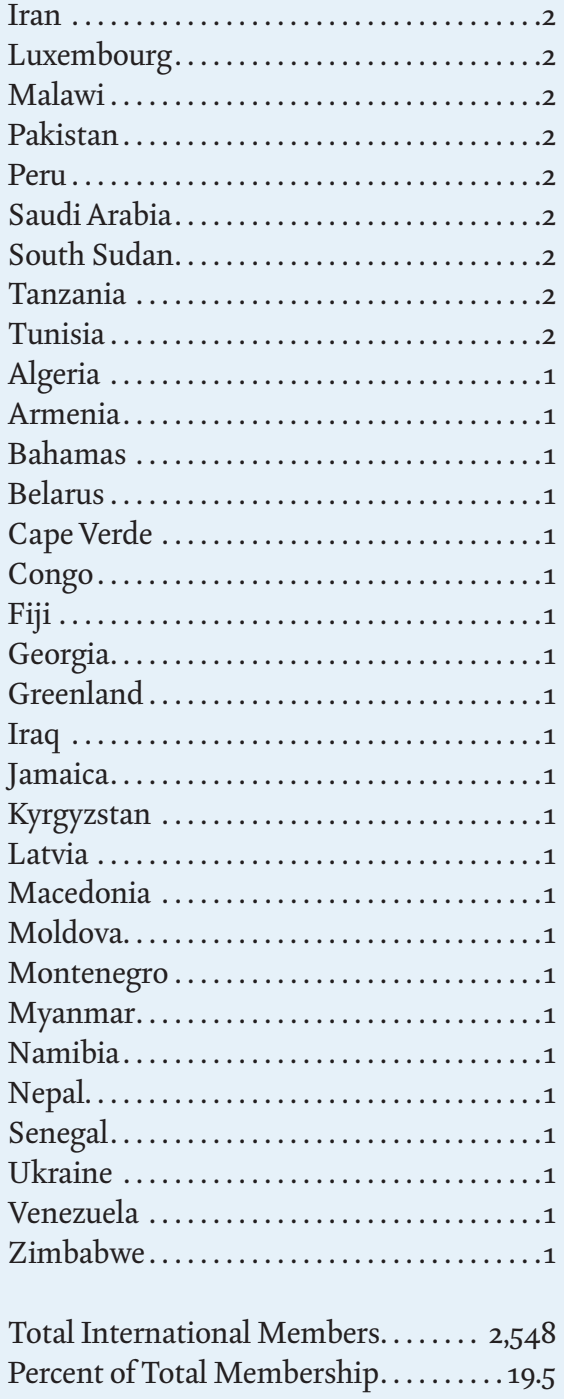

